\title{
MULTI-HOSPITAL VALIDATION OF CRITICAL CARE SIMULATION MODEL
}

\author{
Julie C. Lowery \\ Great Lakes Health Services Research \& Development Field Program \\ Department of Veterans Affairs Medical Center \\ P.O. Box 130170 \\ Ann Arbor, MI 48113-0170, U.S.A.
}

\section{ABSTRACT}

The objective of the study reported herein was to design and validate a general simulation model of a hospital's critical care units, such that with minor changes to the model's input variables, the model can be used to represent the critical care area in a variety of different hospitals. A model was written in GPSS/H and validated for four Department of Veterans Affairs medical centers (VAMCs). The model includes exponential patient interarrival time distributions and lognormal length of stay distributions. The results from this research suggest that a general critical care model can be written which is valid for multiple hospitals. The general model described in this article is easily tailored to the unique patient characteristics and critical care unit configurations of a given hospital.

\section{INTRODUCTION}

The objective of the study reported herein was to design and validate a general simulation model of a hospital's critical care units, such that with minor changes to the model's input variables, the model can be used to represent the critical care area in a variety of different hospitals. The model can then be used to help determine critical care bed requirements, given certain characteristics of a hospital's critical care patient population (i.e., patient arrival rate and length of stay for each unit). By using the model to examine the effects of alternative bed levels on average bed occupancy and number of emergency turnaways (due to lack of available beds), decision-makers can select the bed levels which best meet the hospital's performance objectives.

A number of simulation models of the critical care area and other hospital bed services have been developed for the purpose of determining bed requirements (Clipson and Wehrer, 1973; Cohen, Hershey, and Weiss, 1980; Fetter and Thompson,
1969; Kwak, Kuzdrall, and Schmitz, 1975; Lowery, 1992; Williams, 1983; Zilm and Hollis, 1983). However, few of them have been validated by comparing model predictions with actual hospital performance; and none of them has been validated in more than one hospital, thus limiting their generalizability. This paper describes the validation of a critical care simulation model in four Department of Veterans Affairs medical centers (VAMCs).

The critical care units included in the model are the surgical intensive care unit (SICU), medical intensive care unit (MICU), and coronary care unit (CCU). The model represents patients' arrival to, and lengths of stay in, these units, as well as the flow patterns followed by patients in the event they arrive to find all beds full in the desired unit. To identify these flow patterns and common critical care unit configurations (i.e., does a hospital have separate, specialized units, or combined units?), a survey was sent to 44 medium-sized, medical school-affiliated, tertiary care VAMCs. The results, which were received from 35 VAMCs, show that patient flows through the critical care units follow one of four patterns. These four patterns are summarized in Table 1.

A bed location policy of "accommodate, then bump" indicates that when a bed is not available in the desired unit, the patient is accommodated on another critical care unit. However, if a bed is not available in any of the other critical care units, then an attempt is made to identify a patient in the desired unit who can be "bumped" to the next lower level of care. A policy of "bump, then accommodate" is essentially the reverse. First an effort is made to identify a patient in the desired unit who is eligible for bumping. If one is not available, the incoming patient is accommodated on an alternative unit. As an example, a flow chart of Pattern 1 , which is for a configuration of two units (CCU/MICU and SICU) and an "accommodate, then bump" bed location policy, is presented for SICU arrivals as Figure 1. It should be noted that "bumping" 
Table 1: VA Medical Center (VAMC) Patient Flow Patterns

\begin{tabular}{cccc}
\hline Pattern No. & No. of VAMCs & Unit Configuration* & Bed Location Policy \\
\hline 1 & 13 & 2 & Accommodate, then bump \\
2 & 9 & 3 & Accommodate, then bump \\
3 & 9 & 2 & Bump, then accommodate \\
4 & 4 & 3 & Bump, then accommodate \\
\hline
\end{tabular}

*A unit configuration of "2" refers to a combined CCU/MICU and an SICU. A unit configuration of "3" refers to a separate CCU, MICU, and SICU.

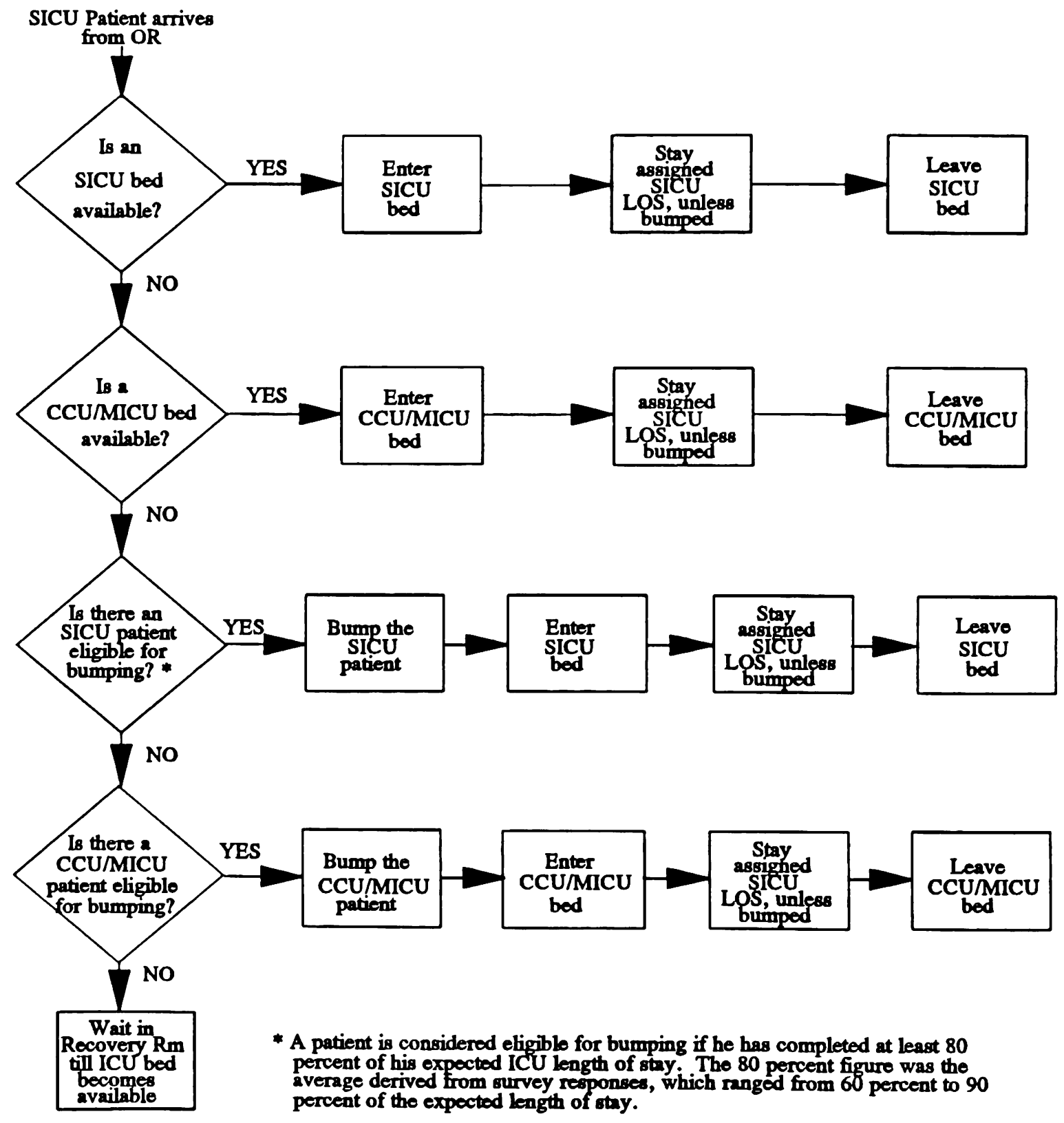

Figure 1: "Accommodate, then Bump" Bed Location Policy for SICU Patients 
a patient does not mean that the patient's care is compromised as a result of the transfer; only that the patient would have stayed longer in the critical care unit if a bed was not needed for an incoming patient. Patients are not bumped unless they are sufficiently stable to be transferred to the next lower level of care.

The simulation model of the patient flow patterns was written in GPSS/H (Henriksen and Crain, 1989). The remainder of this article describes the process of defining the length of stay and interarrival time distributions for, and of validating the model in, four of the 44 VAMCs to which the survey was sent. (The four hospitals were selected based on their ability to readily provide the data required for conducting the research.) All four hospitals follow an "accommodate, then bump" policy for locating beds; three of the four hospitals have three distinct critical care units; the fourth hospital has two units.

\section{LENGTH OF STAY AND INTERARRIVAL TIME DISTRIBUTIONS}

In developing a simulation model that can be used by multiple hospitals, one of the objectives is to keep the major model components as consistent as possible across multiple hospitals, thereby limiting the number of adjustments required for a given hospital to use the model. One of the major components is the shape of the patient interarrival time (IAT) and length of stay (LOS) distributions. For a given unit (i.e., SICU, MICU, or $\mathrm{CCU}$ ) and a given distribution (i.e., interarrival time and length of stay), it is desirable to keep the shape of that distribution the same for all hospitals. If so, each hospital need only supply the values of the distribution's parameters (e.g., mean and variance) to use the model, rather than develop its own empirical distributions or try to fit its historical data to a variety of theoretical distributions.

To identify the theoretical distributions in the four study VAMCs and to determine if they indeed are the same across all four, detailed data on admission and transfer dates and times (to and from the critical care units in each hospital) were obtained and analyzed from each hospital's admission/discharge/transfer (ADT) data base. The data from each VAMC included all admissions and transfers to the CCU, MICU, and SICU from October 1, 1988, through December 31, 1988. This three-month time period may or may not be representative of the admission patterns throughout the year; however, the intent here is to identify the general shape of each distribution, which is assumed to remain relatively constant over time. To the extent that the admission rate increases or decreases with the seasons, or the length of stay increases or decreases with a change in case-type, these changes can be accommodated by the values for the mean LOS and IAT variables. Table 2 presents some general descriptive statistics on the critical care data obtained from the four VAMCs, which were used for determining the shapes of the relevant distributions.

To identify the shape of the required distributions, the computer package UNIFIT was used (Law and Vincent, 1983). UNIFIT is an interactive software program for fitting probability distributions to observed data. Table 3 presents the hypothesized distributions in order of best fit, primarily based on the results of the formal goodness-of-fit tests. However, a review of the graphical presentations of the density and frequency distributions revealed that often two of the hypothesized distributions appeared to represent the sample data equally well.

The decision as to which of the hypothesized distributions should be used in the simulation model for each of the six input distributions required some attention to a practical issue. The method of sampling from a given distribution is much more straightforward for some of the distributions than for others. In particular, the exponential distribution function has already been defined as a GPSS/H function, from which sampling is easily done. Straightforward algorithms are available for sampling from the lognormal and Weibull distributions (Law and Kelton, 1982), with a slightly more cumbersome process available for sampling from the gamma (Fox and Guire, 1976). An algorithm or software for sampling from the inverse Gaussian or Pearson Type $\mathrm{V}$ distributions was not located at the time the study was conducted.

Consequently, it appeared worthwhile to examine closely the differences between some of the second and third ranked distributions in Table 3, to determine the implications of using one of the lower-ranked distributions to facilitate the sampling process. The Pearson Type $\mathbf{V}$ or inverse Gaussian distribution provides a better fit than does the lognormal distribution for MICU LOS in three of the four sample VAMCs. A review of the density and frequency figures for VAMCs A and B showed that the lognormal distribution has a lower proportion of shorter lengths of stay, and a higher proportion of longer lengths of stay, then does the sample data (and, correspondingly, the Pearson Type $\mathrm{V}$ model fitted to the sample data). Therefore, the probable implication of using a lognormal distribution, rather than a Pearson Type V distribution, for MICU LOS would be an over-estimate of the expected occupancy rate and number of turnaways, as higher occupancies are generally associated with longer lengths of stay. Assuming that decision-makers would prefer to err on the high side of 
Table 2: Descriptive Statistics on ICU Admissions in Four VAMCs, October - December 1988

\begin{tabular}{llcccc}
\hline & & \multicolumn{5}{c}{ VAMC } \\
\hline Unit & Statistics & A & B & C & D \\
\hline CCU & Beds & $7 *$ & 4 & 5 & 7 \\
& Total admits & 94 & 89 & 145 & 102 \\
& Avg LOS (Days) & 3.1 & 2.4 & 2.5 & 3.1 \\
\hline \multirow{2}{*}{ MICU } & Beds & -- & 6 & 8 & 7 \\
& Total admits & 62 & 97 & 114 & 78 \\
& Avg LOS (Days) & 3.3 & 3.8 & 3.1 & 4.3 \\
\hline SICU & Beds & 11 & 10 & 8 & 8 \\
& Total admits & 165 & 142 & 108 & 122 \\
& Avg LOS (Days) & 4.4 & 4.1 & 6.8 & 3.4 \\
\hline
\end{tabular}

* CCU and MICU beds are combined into one unit.

Table 3: Fit of Hypothesized Distributions

\begin{tabular}{|c|c|c|c|c|c|}
\hline \multirow[b]{2}{*}{ Data Set } & \multirow[b]{2}{*}{ Order of Fit } & \multicolumn{4}{|c|}{ VAMC } \\
\hline & & A & B & $\mathrm{C}$ & D \\
\hline CCU LOS & $\begin{array}{l}1 \\
2 \\
3\end{array}$ & $\begin{array}{l}\text { Lognormal } \\
\text { Gamma }\end{array}$ & $\begin{array}{l}\text { Gamma } \\
\text { Lognormal }\end{array}$ & $\begin{array}{l}\text { Lognormal } \\
\text { Gamma } \\
\text { Lognormal }\end{array}$ & $\begin{array}{l}\text { Gamma } \\
\text { Inv Gauss }\end{array}$ \\
\hline MICU LOS & $\begin{array}{l}1 \\
2 \\
3\end{array}$ & $\begin{array}{l}\text { Pearson V } \\
\text { Inv Gauss } \\
\text { Lognormal }\end{array}$ & $\begin{array}{l}\text { Pearson V } \\
\text { Inv Gauss } \\
\text { Lognormal }\end{array}$ & $\begin{array}{l}\text { Lognormal } \\
\text { Gamma } \\
\text { Pearson V }\end{array}$ & $\begin{array}{l}\text { Inv Gauss } \\
\text { Lognormal }\end{array}$ \\
\hline SICU LOS & $\begin{array}{l}1 \\
2 \\
3\end{array}$ & $\begin{array}{l}\text { Inv Gauss } \\
\text { Lognormal }\end{array}$ & $\begin{array}{l}\text { Inv Gauss } \\
\text { Lognormal } \\
\text { Gamma }\end{array}$ & $\begin{array}{l}\text { Inv Gauss } \\
\text { Pearson V } \\
\text { Lognormal }\end{array}$ & $\begin{array}{l}\text { Pearson V } \\
\text { Inv Gauss } \\
\text { Lognormal }\end{array}$ \\
\hline CCU IAT & $\begin{array}{l}1 \\
2 \\
3\end{array}$ & $\begin{array}{l}\text { Exponential } \\
\text { Gamma } \\
\text { Weibull }\end{array}$ & $\begin{array}{l}\text { Exponential } \\
\text { Weibull } \\
\text { Gamma }\end{array}$ & $\begin{array}{l}\text { Gamma } \\
\text { Exponential } \\
\text { Weibull }\end{array}$ & $\begin{array}{l}\text { Exponential } \\
\text { Gamma } \\
\text { Weibull }\end{array}$ \\
\hline MICU IAT & $\begin{array}{l}1 \\
2 \\
3\end{array}$ & $\begin{array}{l}\text { Exponential } \\
\text { Gamma } \\
\text { Weibull }\end{array}$ & $\begin{array}{l}\text { Exponential } \\
\text { Gamma }\end{array}$ & $\begin{array}{l}\text { Exponential } \\
\text { Weibull } \\
\text { Gamma }\end{array}$ & $\begin{array}{l}\text { Gamma } \\
\text { Exponential } \\
\text { Weibull }\end{array}$ \\
\hline SICU IAT & $\begin{array}{l}1 \\
2 \\
3\end{array}$ & $\begin{array}{l}\text { Gamma } \\
\text { Weibull } \\
\text { Exponential }\end{array}$ & $\begin{array}{l}\text { Gamma } \\
\text { Weibull } \\
\text { Exponential }\end{array}$ & $\begin{array}{l}\text { Gamma } \\
\text { Weibull } \\
\text { Exponential }\end{array}$ & $\begin{array}{l}\text { Gamma } \\
\text { Weibull } \\
\text { Exponential }\end{array}$ \\
\hline
\end{tabular}

Note: "Inv Gauss" refers to Inverse Gaussian. 
resource predictions (i.e., build slightly more beds than are required, rather than not build enough), use of the lognormal distribution for MICU LOS may produce satisfactory results.

A comparison of the density and frequency figures for the inverse Gaussian and lognormal models fitted to the VAMC D MICU LOS data revealed that both models provide a good representation of the data. Furthermore, given that the lognormal model is the best representation for the VAMC $\mathrm{C}$ data, there is support for selecting the lognormal model for representing MICU LOS in the simulation model.

The inverse Gaussian distribution appears to be the model of choice for the SICU LOS data. However, a review of the density and frequency figures for the inverse Gaussian and lognormal models across all VAMCs revealed that the fit of these two models to the data is very similar. Given the greater ease of sampling from a lognormal model than from an inverse Gaussian model, the lognormal model was used for representing SICU LOS.

The lognormal model is the most representative model for CCU LOS for two of the four VAMCs; but for the other two VAMCs, it provides a similar fit to the gamma model, judging from the density and frequency figures. Again, because of the simplicity of sampling, the lognormal model was selected to represent CCU LOS.

The exponential distribution is clearly the distribution of choice for the CCU and MICU IAT data. For the SICU IAT data, the gamma distribution appears to provide the best fit, judging by the results of the formal goodness-of-fit tests. However, given the greater ease of sampling from an exponential distribution than from a gamma distribution, the exponential distribution was chosen for representing SICU IAT.

In summary, then, the six input distributions selected for use in the simulation model are as follows:

$\begin{array}{ll}\text { CCU LOS: } & \text { Lognormal } \\ \text { MICU LOS: } & \text { Lognormal } \\ \text { SICU LOS: } & \text { Lognormal } \\ \text { CCU IAT: } & \text { Exponential } \\ \text { MICU IAT: } & \text { Exponential } \\ \text { SICU IAT: } & \text { Exponential }\end{array}$

However, to ensure that the selection of these distributions over some of the better fitting distributions would not adversely affect the model's validity to a significant degree, model validation (see the next section) was repeated with the gamma distribution for CCU LOS for VAMCs B and D, and for SICU IAT for all VAMCs.

\section{MODEL VALIDATION}

Validation refers to the process of determining that the model is an accurate representation of the real system. One of the most recommended approaches to helping validate a simulation model of an existing system is to compare the outputs of the real world system with those from the model (Shannon, 1975, p. 227). The outputs of primary interest from the critical care simulation model are the occupancy (or average daily census) of each of three critical care units (i.e., CCU, MICU, and SICU) and the number of turnaways due to lack of available beds. The four VAMC data sets used for identifying the LOS and IAT distributions were also used to calculate the average daily census (ADC), by day, for each VAMC, during the time period October through December 1988. A two-sample $t$ test was used to compare the actual ADC from the four VAMCs with the ADC produced by the simulation model, using the VAMCs' LOS and IAT data, as well as their policies for locating beds, as model input.

The $t$ test requires that the sample observations be independent of one another, which, unfortunately, is not the case for the ADC of a unit from one day to the next. That is, a unit's census on one day is highly correlated to the census on the immediately preceding day, and is likely to be somewhat correlated to the census two days earlier. Therefore, a decision must be made regarding the interval to use in selecting observations from the sample of ADCs, such that the observations are not highly correlated with one another. The UNIFIT computer package produces a correlation plot and scatter diagram of the sample data, which can be used to make an informal assessment of whether the observations in the sample are independent.

Correlation plots and scatter diagrams of ADC were produced and reviewed for each critical care unit in each of the four VAMCs, including one set of figures for the actual data obtained during the study period ( 85 days), and another set of figures obtained from a simulated period of 360 days, following a 90 day warmup period. (A three-month warmup period allowed sufficient time for the simulation to reach steady-state.) Plots were produced at intervals equal to one (every day), two (every other day), three (every third day), and four (every fourth day). Based on these results, an interval of width three was selected for defining the validation samples. This interval size appeared to eliminate the correlation in the majority of the samples (16 out of 23 , or 70 percent), with the remainder requiring an interval of width four. Using four as the interval width, however, would produce a sample size of only 22 for the actual data from the VAMCs; and the reduction in correlation obtained from increasing the interval width from three to four did not appear to be substantial in many of the samples. 
Table 4: Results of Model Validation

\begin{tabular}{|c|c|c|c|c|c|c|}
\hline \multicolumn{3}{|c|}{$\begin{array}{l}\text { Actual Data } \\
\quad(n=29)\end{array}$} & \multicolumn{2}{|c|}{$\begin{array}{l}\text { Model Data } \\
(n=240)\end{array}$} & \multicolumn{2}{|c|}{$\begin{array}{c}\text { Comparison of Actual and } \\
\text { Model Means }\end{array}$} \\
\hline VAMC/Unit & $\begin{array}{l}\text { Mean } \\
\text { ADC }\end{array}$ & $\begin{array}{l}\text { S.D. } \\
\text { ADC }\end{array}$ & $\begin{array}{l}\text { Mean } \\
\text { ADC }\end{array}$ & $\begin{array}{l}\text { S.D. } \\
\text { ADC }\end{array}$ & $T$-stat & $\begin{array}{c}P \text {-value } \\
=\operatorname{Pr}\{T \text { stat }>\}\end{array}$ \\
\hline $\begin{array}{l}\text { VAMC A } \\
\text { CCU/MICU } \\
\text { SICU }\end{array}$ & $\begin{array}{l}5.31 \\
8.66\end{array}$ & $\begin{array}{l}1.39 \\
1.78\end{array}$ & $\begin{array}{l}5.38 \\
8.28\end{array}$ & $\begin{array}{l}1.67 \\
2.40\end{array}$ & $\begin{array}{r}-.22 \\
.82\end{array}$ & $\begin{array}{r}>.80 \\
.41\end{array}$ \\
\hline $\begin{array}{l}\text { VAMC B } \\
\text { CCU } \\
\text { MICU } \\
\text { SICU }\end{array}$ & $\begin{array}{l}2.34 \\
3.90 \\
6.86\end{array}$ & $\begin{array}{l}1.26 \\
1.90 \\
2.08\end{array}$ & $\begin{array}{l}2.41 \\
3.75 \\
6.60\end{array}$ & $\begin{array}{l}1.19 \\
1.57 \\
2.16\end{array}$ & $\begin{array}{r}-.30 \\
.47 \\
.61\end{array}$ & $\begin{array}{l}.77 \\
.64 \\
.55\end{array}$ \\
\hline $\begin{array}{l}\text { VAMC C } \\
\text { CCU } \\
\text { MICU } \\
\text { SICU }\end{array}$ & $\begin{array}{l}4.34 \\
5.72 \\
6.31\end{array}$ & $\begin{array}{l}1.59 \\
1.39 \\
1.07\end{array}$ & $\begin{array}{l}4.05 \\
6.02 \\
6.24\end{array}$ & $\begin{array}{l}1.19 \\
1.76 \\
1.69\end{array}$ & $\begin{array}{r}1.19 \\
-.88 \\
.22\end{array}$ & $\begin{array}{r}.24 \\
.38 \\
>.80\end{array}$ \\
\hline $\begin{array}{l}\text { VAMC D } \\
\text { CCU } \\
\text { MICU } \\
\text { SICU }\end{array}$ & $\begin{array}{l}3.83 \\
3.03 \\
4.45\end{array}$ & $\begin{array}{l}1.14 \\
1.55 \\
1.38\end{array}$ & $\begin{array}{l}3.54 \\
3.31 \\
4.21\end{array}$ & $\begin{array}{l}1.78 \\
1.70 \\
2.06\end{array}$ & $\begin{array}{r}.86 \\
-.85 \\
.61\end{array}$ & $\begin{array}{l}.39 \\
.40 \\
.55\end{array}$ \\
\hline
\end{tabular}

In summary, then, the validation consisted of comparing the following: actual ADC, October through December 1988, every third observation $(n=29)$; and model ADC, two-year simulation (after three-month warmup), every third observation $(n=240)$. A length of two years was chosen for the simulation run in order to generate a sufficient number of randomly sampled observations from the LOS and IAT distributions for obtaining the average values actually experienced by the sample of VAMCs. The results of the validation are presented in Table 4. For all of the comparisons, the $P$-value is $>.20$, suggesting the ADCs of the two sample populations are not significantly different. That is, the hypothesis that the means of the two populations are the same cannot be rejected for all of the units in all of the sample VAMCs. The statistical tests provide no evidence of model inadequacy.

Turnaway data are not routinely collected within the VAMCs, and were not available during the same time period for which the ADC were obtained. However, turnaway data were collected by the participating hospitals for this study during the time period April through June 1989. Unfortunately, a rigorous test for the equality of the number of turnaways could not be performed, because of an inadequate sample size of the actual turnaway data, which were collected during a period of three months. Unlike the ADC observations, which are measured daily, the number of turnaways is generally measured over a time period of at least one month, because of the small numbers that occur. Thus, the sample size would be only three. Consequently, an informal comparison of actual versus model turnaways must be used for the validation. The results of this comparison are presented in Table 5.

Table 5: Turnaways/Month: Actual versus Model

\begin{tabular}{lcc}
\hline VAMC & Actual & Model \\
\hline A & 7 & 2 \\
B & 0 & 0 \\
C & 0 & 1 \\
D & 1 & 0 \\
\hline
\end{tabular}

One of the reasons for the large discrepancy in VAMC A between the actual number of monthly turnaways and the number predicted by the model $(7$ 


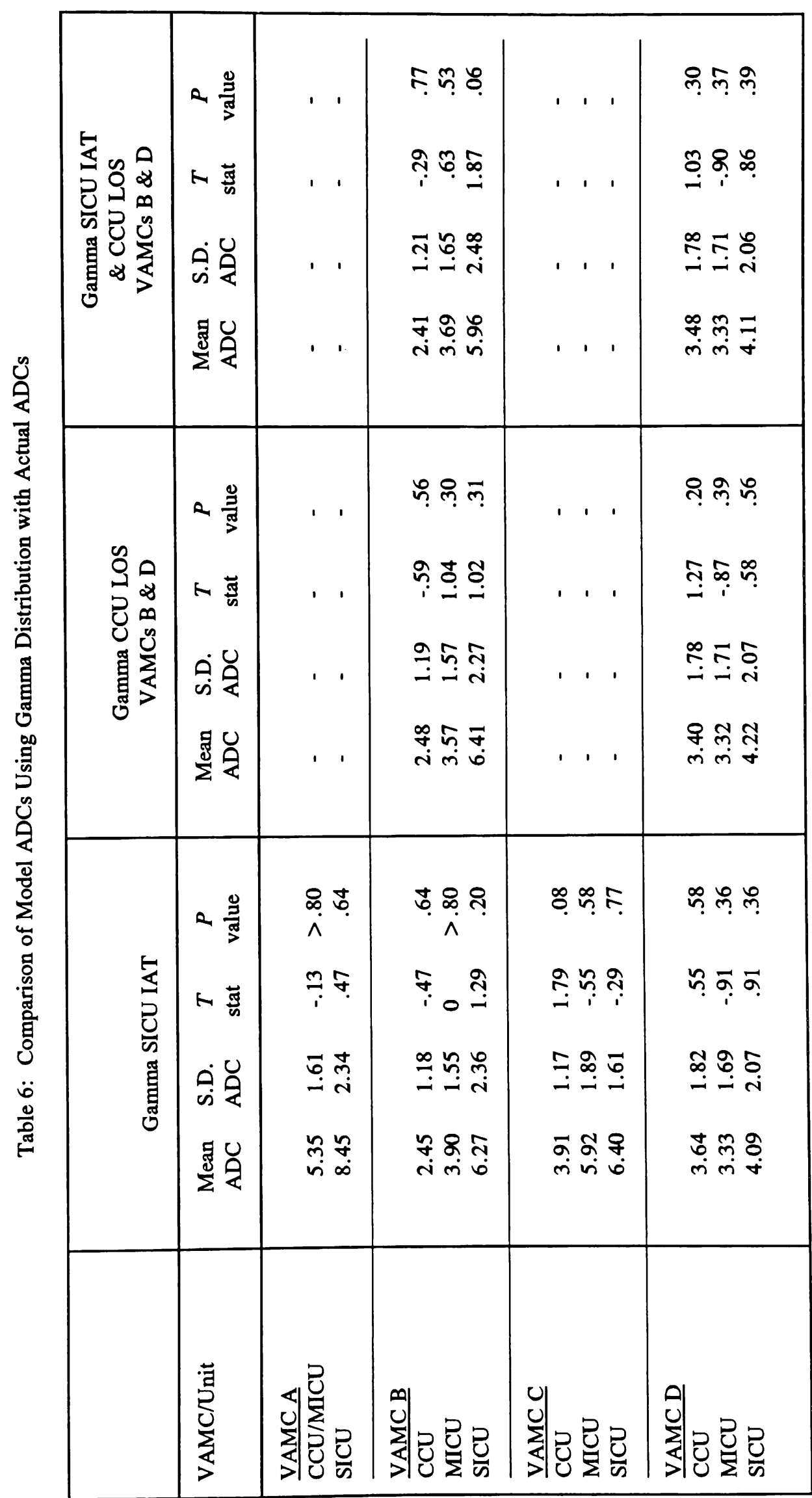


versus 2 , respectively) is that the admission rate for the time period during which the actual turnaway data were collected (April through June 1989) was considerably higher than the rate used as model input (401 admissions versus 321 , respectively). Recall that the admission rate used as input to the model was taken from the actual admission rate during October through December 1988, in order to validate the ADCs produced by the model. (Actual ADC data were collected during this same time period.) The model was rerun for VAMC A using the admission rates for April through June 1989, and the model predicted a total of five turnaways, which more closely resembles the number that actually occurred during that same time period.

Finally, Table 6 presents the results of comparing the actual ADCs with the model ADCs when two of the CCU LOS distributions, and all of the SICU IAT distributions, in the model follow a gamma distribution, rather than a lognormal and exponential distribution, respectively. Three combinations using the gamma distribution as an alternative were tried: (1) gamma SICU IAT, with all other distributions remaining the same; (2) gamma CCU LOS for VAMCs $\mathrm{B}$ and $\mathrm{D}$, with all other distributions remaining the same; and (3) gamma SICU IAT, gamma CCU LOS (VAMCs B and D), with all other distributions remaining the same. The results of the $t$ tests show increases in the value of the $T$ statistic for some of the units in some of the VAMCs, and decreases in the values for others. For any given VAMC, however, there is no overall decrease in the values of the $T$ statistics. One can conclude, therefore, that use of the gamma distribution does not appear to improve the validity of the simulation model.

\section{CONCLUSION}

The results from this research suggest that a general critical care model can be written which is valid for multiple hospitals. The general model described in this article is easily tailored to the unique patient characteristics and critical care unit configurations of a given hospital. Specifically, the model requires the following data as model input to tailor its use to a given hospital:

(1) Average IAT of patients, for each critical care unit (calculated directly from total admissions during a given time period)

(2) Average LOS of patients, for each critical care unit

(3) Variance of LOS, for each critical care unit

(4) Number of beds in each critical care unit

(5) Unit configuration (CCU and MICU separate or combined?)

Variables (1), (2), and (3) define the parameters of the IAT and LOS distributions. (Note that the exponential distribution is a single-parameter distribution, because the mean is equal to the standard deviation.) The values for each of the above input variables are easily supplied by the user, and do not require rewriting any of the model's GPSS/H code.

The research also demonstrates the benefit of using theoretical distributions as model input, rather than empirical distributions. If it can be demonstrated (as was done in this research) that a theoretical distribution works well for multiple facilities, it is easier for each facility to simply enter the distributions ${ }^{\circ}$ parameters as model input, rather than develop its own empirical distributions from historical data. Furthermore, the research demonstrated the benefits of conducting a sensitivity analysis of the model's validity to different distribution types. The results of the analysis showed that a model with "simpler" input distributions (in terms of modeling) work as well as a model with more complicated input distributions, even though the more complicated distributions provide better representations of the actual input data.

Additional research is needed to provide more confidence in the model's ability to accurately represent the critical care area in different types of hospitals, including hospitals with different bed location policies. Current research involves expanding the model to include intermediate care units, and to validate the model in approximately $40 \mathrm{VA}$ medical centers.

\section{REFERENCES}

Clipson, C.W., and J.J. Wehrer. 1973. Planning for Cardiac Care. Ann Arbor, MI: Health Administration Press.

Cohen, M.A., J.C. Hershey, and E.N. Weiss. 1980. Analysis of capacity decisions for progressive patient care hospital facilities. Health Services Research 15(2): 145-160.

Fetter, R.B., J.D. Thompson. 1969. A decision model for the design and operation of a progressive care hospital. Medical Care 7(6):450-462.

Fox, D.J., and K.E. Guire. 1976. Documentation for $M I D A S$. Ann Arbor, MI: The Statistical Research Laboratory, The University of Michigan.

Henriksen, J.O. and R.C. Crain. 1989. GPSS/H Reference Manual. Annandale, VA: Wolverine Software Corporation.

Kwak, N.K., P.J. Kuzdrall, and H. Schmitz. 1975. Simulating the use of space in a hospital surgical suite. Simulation 25(5):147-151.

Law, A.M., and W.D. Kelton. 1991. Simulation 
Modeling and Analysis. New York: McGraw Hill Book Company.

Law, A.M., S.G. Vincent. 1983. UNIFIT: An Interactive Computer Package for Fitting Probability Distributions to Observed Data. Tucson: Averill M. Law and Stephen G. Vincent.

Lowery, J.C. 1992. Simulation of a hospital's surgical suite and critical care area. In Proceedings of the 1992 Winter Simulation Conference, ed. J.J. Swain, D. Goldsman, and R.C. Crain, 1071-1078. Baltimore: Association for Computing Machinery.

Shannon, R.E. 1975. Systems Simulation: The Art and Science. Englewood Cliffs, N.J.: Prentice-Hall, Inc.

Williams, S.V. 1983. How many intensive care beds are enough? Critical Care Medicine 11(6):412-416.

Zilm, F., and R.B. Hollis. 1983 An application of simulation modeling to surgical intensive care bed need analysis. Hospital and Health Services Administration September/October:82-101.

\section{AUTHOR BIOGRAPHY}

JULIE C. LOWERY is employed as a health services research scientist at the Great Lakes Health Services Research and Development Field Program, VA Medical Center, Ann Arbor, MI. She received a B.S. in Microbiology from the University of Michigan in 1977, and a Masters in Health Services Administration, also from the University of Michigan, in 1979. In 1991 she received her doctorate in Health Services Organization and Policy from the School of Public Health, University of Michigan, where she specialized in operations research and information systems in health care. In addition to the simulation of health care systems, Dr. Lowery's research interests include the development and validation of staffing and scheduling methodologies. 